\begin{tabular}{|c|c|}
\hline Citation & $\begin{array}{l}\text { Swinnen B, Saegeman V, (2019), } \\
\text { Predictive value of JC virus PCR in cerebrospinal fluid in the diagnosis } \\
\text { of PML } \\
\text { Diagn Microbiol Infect Dis. } 2019 \text { Jun } 26\end{array}$ \\
\hline Archived version & $\begin{array}{l}\text { Author manuscript: the content is identical to the content of the published } \\
\text { paper, but without the final typesetting by the publisher }\end{array}$ \\
\hline Published version & http://dx.doi.org/10.1016/j.diagmicrobio.2019.06.011 \\
\hline Journal homepage & Diagnostic Microbiology and Infectious Disease \\
\hline Author contact & $\begin{array}{l}\text { greet.vandenberghe@kuleuven.be } \\
+32(0) 16344021\end{array}$ \\
\hline IR & https://lirias2.kuleuven.be/viewobject.html?cid=1\&id=2826151 \\
\hline
\end{tabular}

(article begins on next page) 


\title{
Predictive value of JC virus PCR in cerebrospinal fluid in the diagnosis of PML
}

\author{
Bart Swinnen $^{\text {a,b,c,*, }}$ Veroniek Saegeman ${ }^{\mathrm{d}}$, Kurt Beuselinck ${ }^{\mathrm{d}}$, Anke Wouters ${ }^{\mathrm{a}, \mathrm{b}, \mathrm{c}}$, Gert Cypers ${ }^{\mathrm{e}}$, \\ Geert Meyfroidt ${ }^{\mathrm{f}}$, Maarten Schrooten ${ }^{\mathrm{a}, \mathrm{g}}$ \\ a Neurology Department, University Hospitals Leuven, Leuven, Belgium \\ ${ }^{\mathrm{b}}$ KU Leuven - University of Leuven, Department of Neurosciences, Experimental Neurology and Leuven Brain Institute (LBI), Leuven, Belgium \\ ' VIB, Center for Brain E' Disease Research, Laboratory of Neurobiology, Leuven, Belgium \\ d Department of Laboratory Medicine, University Hospitals Leuven, Leuven, Belgium \\ e Department of Neurology, OLV Hospital Aalst, Aalst, Belgium \\ ${ }^{\mathrm{f}}$ Intensive Care Medicine Department, University Hospitals Leuven, Leuven, Belgium \\ ${ }^{\mathrm{g}}$ Laboratory for Cognitive Neurology, Department of Neurosciences, KU Leuven, Leuven, Belgium
}

\section{A B S T R A C T}

Objective: To assess the predictive value of JC virus (JCV) PCR in cerebrospinal fluid (CSF) in the diagnosis of pro-gressive multifocal leukoencephalopathy (PML).

Methods: We conducted a retrospective database query to identify patients with positive CSF JCV PCR. Clinical fea-tures, final diagnosis and quantitative PCR results were obtained.

Results: A positive CSF JCV PCR had a PPV of $10.4 \%$ for the diagnosis of PML. A weakly positive PCR had a PPV of $1.6 \%$, whereas a moderately to highly positive PCR had a PPV of $92.3 \%$. A PPV of $0.0 \%$ was observed in immuno-competent patients and in patients without compatible clinical or radiological features. Conclusions: A false-positive CSF JCV PCR is highly prevalent in our clinical practice. This test should be reserved for patients with a clinical suspicion of PML and the quantitative result of the PCR should be taken into account when making the diagnosis of PML.

\section{Introduction}

Progressive multifocal leukoencephalopathy (PML) is a neuroinfectious disease caused by the JC polyomavirus (JCV). It is highly uncommon in immunocompetent persons and almost always occurs in the setting of an acquired immunosuppressive condition, with AIDS and natalizumab treatment being the most frequent (Bauer et al., 2015). Because of atypical clinical and radiological features, diagnosis is often not straightforward. According to the current diagnostic criteria, definite PML can be diagnosed in two ways (Berger et al., 2013). First, in case a brain biopsy has been performed, a definite diagnosis can be established based on histopathology. A second manner to definitely diagnose PML is through compatible clinical and radiological features together with a positive cerebrospinal fluid (CSF) JCV polymerase chain

\footnotetext{
* Corresponding author. Tel.: +3216344285.

E-mail addresses: bart.swinnen@uzleuven.be (B. Swinnen), veroniek.saegeman@uzleuven.be (V. Saegeman), kurt.beuselinck@uzleuven.be (K. Beuselinck), anke.wouters@uzleuven.be (A. Wouters), gert.cypers@olvz-aalst.be (G. Cypers), geert.meyfroidt@uzleuven.be (G. Meyfroidt), maarten.schrooten@uzleuven.be (M. Schrooten).
}

reaction (PCR). The presence of either compatible clinical or radiological features is considered as 'probable PML'. In practice, brain biopsy is only rarely performed and clinical and radiological features lack specificity. Hence, diagnosis heavily relies on CSF JCV PCR. According to available literature, qualitative CSF JCV PCR is regarded as highly sensitive and specific with a high positive predictive value (PPV) for the diagnosis of PML (Berger et al., 2013; Fong et al., 1995; Iacobaeus et al., 2009; McGuire et al., 1995).

We wanted to analyze the PPV of quantitative CSF JCV PCR testing in clinical practice. Our second aim was to assess whether a particular JCV PCR profile in accompanying blood and/or urine samples would be of additional diagnostic value. Finally, we performed a literature review, identifying series where CSF JCV PCR was performed to calculate its PPV and compare it to this cohort's PPV.

\section{Materials and methods}

\subsection{Database query}

A query searching for all JCV PCRs performed on clinical samples was performed on the database of the clinical laboratory of the University 
Hospitals Leuven between January 2004 and December 2014. For all patients with a positive CSF JCV PCR, the final diagnosis was obtained and verified (based on clinical course, radiological features and/or brain biopsy) by examining the corresponding electronic medical record. Additionally, clinical and radiological features at the time of lumbar puncture were obtained. The query was conducted with permission from the local ethics committee (local study code S57675).

\section{2. $P C R$}

CSF, plasma and urine samples were extracted by means of NucliSens easyMAG (bioMérieux, Marcy l'Etoile, France). All samples were extracted within a time lag of 48 hours. Deoxyribonucleic acid (DNA) extracts subsequently were analyzed with in-house real-time PCR Taqman (ABI7900) according to the method previously described (Beuselinck et al., 2005; Herman et al., 2004). JC virus and BK virus are both a polyomavirus strain causing disease in humans. Both viruses cause distinct infections in immunocompromised patients, i.e. neurological disease and renal disease, respectively. Therefore, a common quantitative real-time PCR detecting both JC and BK virus was developed in the year 1997. The primers of the in-house JC/BK PCR target a region of the large $\mathrm{T}$ antigen present both in $\mathrm{JC}$ and $\mathrm{BK}$ virus (Beuselinck et al., 2005; Herman et al., 2004). These primers were used to amplify DNA and detection was done with a probe complementary to an internal target sequence present in both BK and JC virus PCR amplicons (Herman et al., 2004). For each virus, a standard curve was used to quantify the amount of DNA; based on duplicate internal standard samples, the quantifiable range was constituted by values between $2.7 \log$ copies/mL (i.e. 500 copies/mL) and $6.7 \log$ copies/mL (i.e. $5,000,000 \log$ copies $/ \mathrm{mL}$ ). Hence, the following cut-offs were therefore used in routine samples: weakly positive $(<2.7 \log$ copies $/ \mathrm{mL}$, not quantifiable), moderately positive ( $\leq 6.7 \log$ copies/mL, quantifiable), strongly positive (>6.7 log copies/mL, not quantifiable).

For validation of quantification, we used plasmid derived JCV clones with the complete JCV genome cloned in the EcoRI site of the multiple cloning site of the pBR322 vector (courtesy of TH Weber, Marienkrankenhaus, Hamburg, Germany). The inserted sequence was quantitated using ultraviolet spectrophotometry to calculate the copy number for a master standard positive control.

From 2007 onwards, we yearly participate at the QCMD External quality assessment scheme for JCV/BK virus with good results.

The detection limit of the PCR was lower than 500 copies/mL, but $100 \%$ of the samples were detected at the cutoff of 500 copies $/ \mathrm{mL}$. Since February 29th 2012, PCR reaction is repeated on samples with weakly positive $\mathrm{Ct}$ (cycle threshold) values higher than 37.3 (i.e. $<2.7$ $\log$ copies $/ \mathrm{mL}$ ) and only the repeat value is reported. Weakly positive samples were negative after repetition in $67 \%$ of the cases. In every PCR run a positive and negative control is included, the run is repeated in case of positivity in the negative control.

\subsection{Literature review}

For the literature review, the PubMed database was searched with the following terms: 'JCV', 'polyoma', 'PCR' and 'PML'. Papers concerning series of patients with CSF JCV PCR were included and the number of true- and false-positive PCRs were deducted.

\subsection{Statistics}

Odds ratio (OR) and PPV were performed in GraphPad Prism 7.01 (GraphPad Software, San Diego, USA) using Fisher's exact test and the Wilson-Brown method. Significance level was set at 0.05 . ROC analysis was performed with R statistical software 3.2.2 (R Core Team (2015). $\mathrm{R}$ : A language and environment for statistical computing. $\mathrm{R}$ Foundation for Statistical Computing, Vienna, Austria. URL https://www.R-project. org). The optimal threshold was defined by the Youden index.

\section{Results}

The query (Fig. 1) yielded a total of 1130 patients in whom CSF JCV PCR was performed. In 233 (20.6\%) of these patients PCR was positive. After excluding patients from other hospitals (of whom we did not have access to the electronic medical record), 135 (57.9\%) patients with a positive CSF JCV PCR remained in the final analysis (later referred to as the index population).

Fourteen patients were finally diagnosed with PML whereas 121 received another diagnosis, resulting in a PPV of $10.4 \%$ (95\% CI: $6.3-16.7 \%$ ) (Fig. 1). Alternative diagnoses comprise toxic-metabolic encephalopathy $(n=34)$, central nervous system (CNS) infection $(n=27$; i.e. bacterial, viral, fungal and parasitic meningitis/encephalitis), CNS tumor ( $\mathrm{n}=17$; e.g. lymphoma, neoplastic meningitis and astrocytoma), CNS inflammatory disease $(n=16$; e.g. multiple sclerosis, paraneoplastic encephalitis and vasculitis), neurodegenerative disease $(n=10$; e.g. Creutzfeldt-Jakob disease, amyotrophic lateral sclerosis and vascular dementia), posterior reversible encephalopathy syndrome $(n=6)$, primary headache $(n=3)$, psychiatric disorder $(n=3)$, stroke $(n=3)$ and cranial nerve palsy $(\mathrm{n}=2)$. Of these non-PML cases, 77 (63.6\%) were immunocompromised due to immunosuppressive medication ( $\mathrm{n}=43$; one patient treated with natalizumab), chemotherapy $(\mathrm{n}=$ $15)$, AIDS ( $n=12)$, hematological malignancy $(n=5)$ or primary immune deficiency $(\mathrm{n}=2)$.

Subsequently, the index population was stratified according to the degree of PCR positivity. Only two of 122 patients with a weakly positive (i.e. $<2.7 \log$ copies $/ \mathrm{ml}$, not quantifiable) PCR were diagnosed with PML ( $\mathrm{PPV}=1.6 \%, 95 \% \mathrm{CI}: 0.3-5.8 \%$ ), whereas 12 of the 13 patients with a moderately or strongly positive ( $\geq 2.7 \mathrm{log}$ copies $/ \mathrm{ml}$ ) PCR received a final diagnosis of PML (PPV = 92.3\%, 95\% CI: 66.7-99.6\%) (Fig. 1). Twelve patients had a moderately positive $(\leq 6.7 \log$ copies/mL) PCR, of whom 11 were diagnosed with PML. The one patient without PML but with a moderately positive PCR had a viral load of 2.85 log copies/ $\mathrm{ml}$, which is only marginally above the quantification threshold (Fig. 2a). Most PML patients with a moderately positive PCR had viral loads above $3.0 \log$ copies/mL (Fig. 2a). Only one patient had a strongly positive ( $>6.7$ log copies, not quantifiable) PCR, he was diagnosed with PML (Fig. 2a). In total 14.3\% (2/14) of PML patients had a weakly positive CSF JCV PCR.

Next, we performed an ROC analysis to identify the viral load with optimal cut-off value to detect PML patients in case of a positive CSF JCV PCR. ROC analysis identified an area under the curve (AUC) of 0.93 (95\% CI: 0.83-1.00) (Fig. 2b) with an optimal threshold of 2.82 log copies to detect PML patients. This corresponds to a sensitivity of $86 \%$ (95\% CI: $57-98 \%$ ) and a specificity of $99 \%$ (95\% CI: $95-100 \%$ ).

Next, to assess whether the indication for CSF JCV PCR testing is related to the PPV, clinical and radiological features at the time of lumbar puncture were analyzed (Table 1). Analysis irrespective of the immune status revealed a PPV of 0.0\% (95\% CI: 0.0-4.8\%) when compatible clinical and radiological features were absent. PPV gradually increased with increasing compatible features, reaching a PPV of $48.0 \%$ (95\% CI: 30.0-66.5\%) in case of both compatible clinical and radiological features. Analysis taking into account the immune status revealed a PPV of $0.0 \%$ (95\% CI: 0.0-8.0\%) in immunocompetent patients. In immunocompromised patients, PPV was 15.4\% (95\% CI: 9.4-24.2\%), with the PPV again gradually increasing with increasing compatible features, reaching $70.6 \%$ (95\% CI: 46.9-86.7\%) in case of both compatible clinical and radiological features (i.e. patients with 'definite PML'). For this latter group of patients clinical features, radiological features, underlying disorder, immune suppression state, diagnosis and JCV PCR titer are displayed in Table 2. When the quantitative result of the CSF JCV PCR was also taken into account, PPV further increased to $100.0 \%$ (95\% CI: 74.1-100.0).

Next, we analyzed the performance of CSF JCV PCR before versus after implementing repeated testing of weakly positive samples. Before implementation, 10 out of 128 patients had PML (PPV $=7.8 \%, 95 \% \mathrm{CI}$ : 


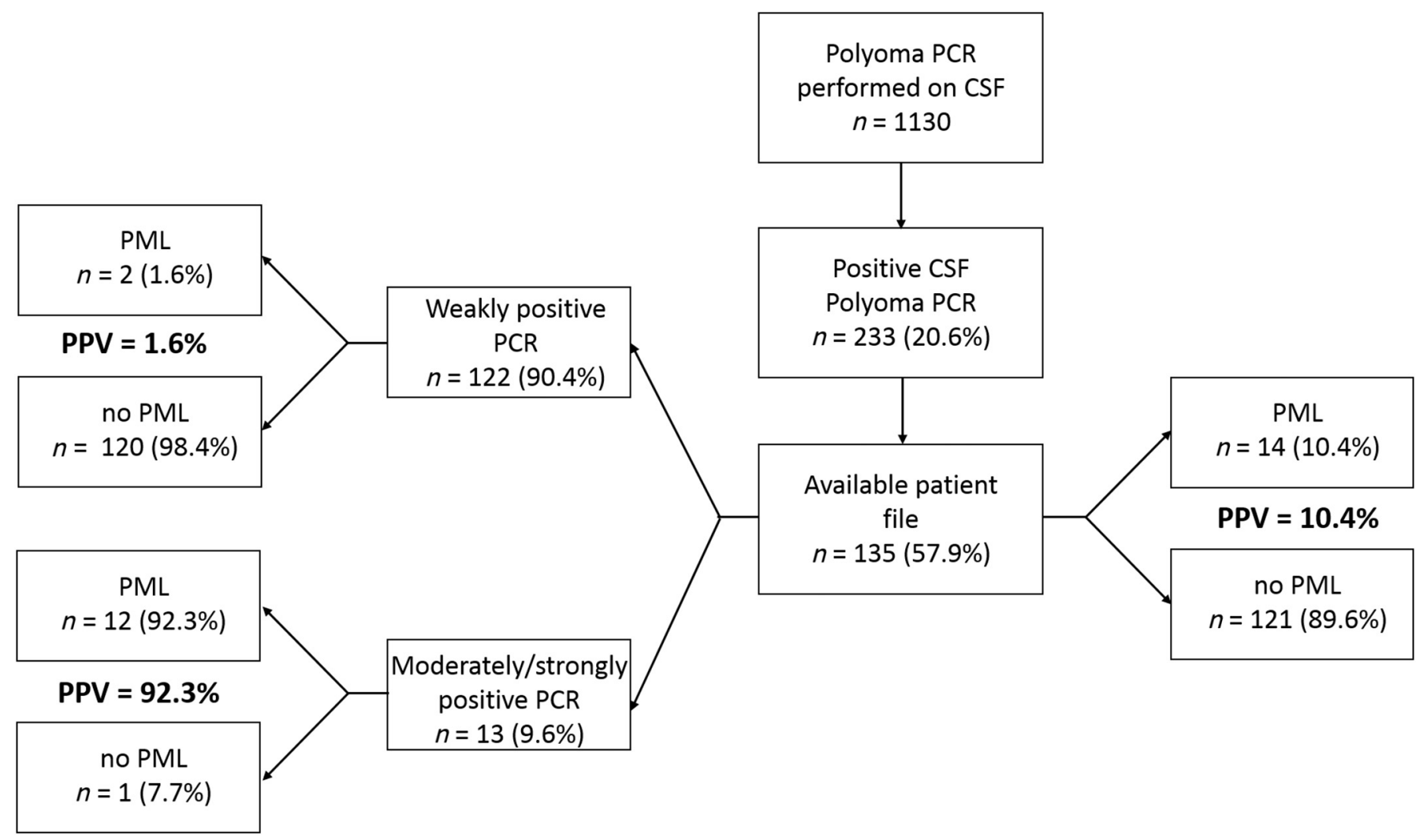

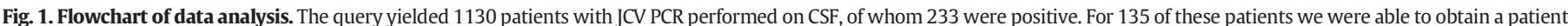
file. A weakly positive PCR is defined as a viral load $<2.7 \log$ copies $/ \mathrm{mL}$, whereas a moderately/strongly positive PCR is defined as a viral load $\geq 2.7 \log$ copies/mL.

4.3-13.8\%), whereas afterwards 4 out of 7 patients had PML (PPV = $57.1 \%$, 95\% CI: $25.0 \%-84.2 \%)$. Hence, retesting of weakly positive PCRs significantly decreased the amount of false positives ( $O R=0.06,95 \%$ CI: $0.02-0.27, P=0.002)$ ).

Next, we aimed to assess whether JCV PCR results in blood and/or urine might have an additional diagnostic value. Blood JCV PCR was performed in 27 patients of the index population (Fig. 3). Twenty (74.1\%) PCRs were positive. Three (15\%) of the patients with a positive blood JCV PCR had PML, whereas three (42.9\%) of the patients with a negative blood JCV PCR had PML. Hence, additionally having a positive blood PCR does not increase the chances of having PML when compared to a negative blood PCR ( $\mathrm{OR}=0.24(95 \% \mathrm{CI}: 0.04-1.39, P=0.29)$ ).
A

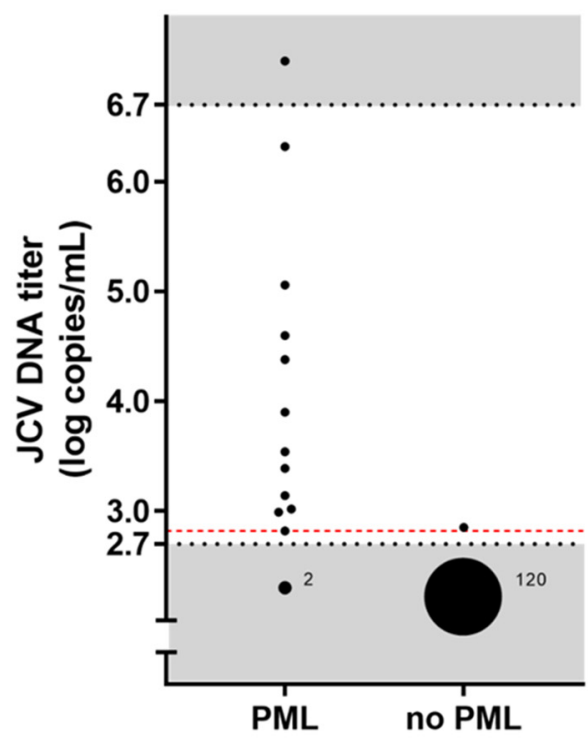

B

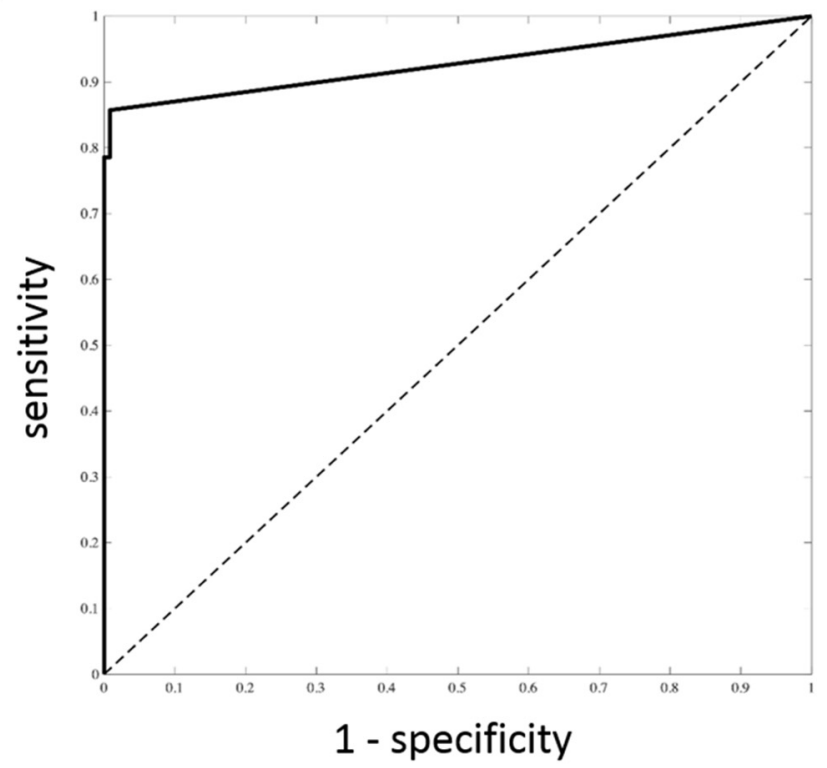

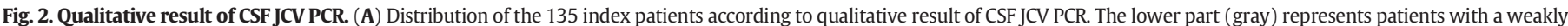

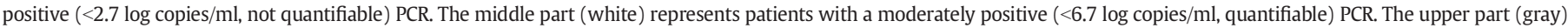

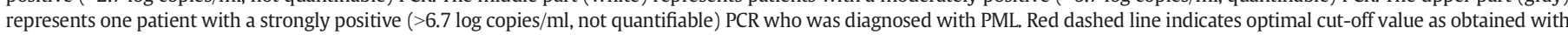
Youden index. (B) ROC curve of JCV DNA viral load to predict diagnosis of PML (AUC $=0.93$ ). 
Table 1

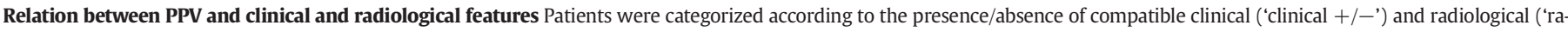

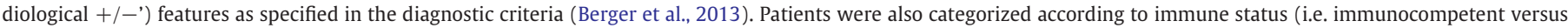
immunocompromised).

\begin{tabular}{|c|c|c|c|c|c|c|c|}
\hline & & & (n) & $(\%)$ & PML diagnosis $(\mathrm{n})$ & PPV & CI $95 \%$ \\
\hline \multirow[t]{6}{*}{ Irrespective of immune status } & & & 135 & 100.0 & 14 & 10.4 & $6.3-16.7$ \\
\hline & Clinical - & Radiological - & 77 & 57.0 & 0 & 0.0 & $0.0-4.8$ \\
\hline & Clinical + & Radiological - & 28 & 20.7 & 1 & 3.6 & $0.2-17.7$ \\
\hline & Clinical - & Radiological + & 5 & 3.7 & 1 & 20.0 & $1.0-62.4$ \\
\hline & Either clinic & ological + & 33 & 24.4 & 2 & 6.1 & $1.1-19.6$ \\
\hline & Clinical + & Radiological + & 25 & 18.5 & 12 & 48.0 & $30.0-66.5$ \\
\hline \multirow[t]{4}{*}{ Immunocompromised } & & & 91 & 67.4 & 14 & 15.4 & $9.4-24.2$ \\
\hline & Clinical - & Radiological - & 50 & 54.9 & 0 & 0.0 & $0.0-7.1$ \\
\hline & Clinical + & Radiological - & 22 & 24.2 & 1 & 4.5 & $0.2-21.8$ \\
\hline & Clinical - & Radiological + & 2 & 2.2 & 1 & 50.0 & $2.6-97.4$ \\
\hline \multirow{2}{*}{ Probable PML } & Either clinic & ological + & 24 & 26.4 & 2 & 8.3 & $1.5-25.8$ \\
\hline & \& viral load & copies $/ \mathrm{mL}$ & 1 & 0.7 & 1 & 100.0 & $5.1-100.0$ \\
\hline \multirow{2}{*}{ Definite PML } & Clinical + & Radiological + & 17 & 18.7 & 12 & 70.6 & $46.9-86.7$ \\
\hline & \& viral load & copies $/ \mathrm{mL}$ & 11 & 8.1 & 11 & 100.0 & $74.1-100.0$ \\
\hline Immunocompetent & & & 44 & 32.6 & 0 & 0.0 & $0.0-8.0$ \\
\hline
\end{tabular}

Urine JCV PCR was performed in 32 patients of the index population (Fig. 3). Thirty-one (96.9\%) of these PCRs were positive and one was negative. Five $(16.1 \%)$ of the patients with positive urine JCV PCR had PML. The one patient with a negative urine JCV PCR was not diagnosed with PML. Although odds ratio can't be calculated, additionally having a positive urine PCR does not increase the chance of having PML when compared to a negative urine PCR.

Finally, JCV PCR was performed on both urine and blood in 19 patients of the index population (Fig. 3). Sixteen of these index patients had positive PCRs both in blood and urine. Three (18.7\%) of those were diagnosed with PML. In three patients the PCR was negative in blood and positive in urine, one of these patients was diagnosed with PML. There were no patients with negative PCR in both blood and urine, or positive PCR in blood and negative in urine. Hence, additionally having a positive PCR in both blood and urine does not increase the chance of having PML when compared to a negative PCR in blood and/ or urine $(\mathrm{OR}=0.46(95 \% \mathrm{CI}$ : $0.04-8.74, P=0.53)$ ).

Review of the literature identified fifteen studies where JCV PCR had been performed on CSF in a large $(n>30)$ series of patients (Table 3$)$ (Alvarez-Lafuente et al., 2007; Behzad-Behbahani et al., 2003; Ferrante et al., 1997, 1998; Fink et al., 2006; Fong et al., 1995; Gibson et al., 1993; Hammarin et al., 1996; Iacobaeus et al., 2009, 2013; Koralnik et al., 1999; McGuire et al., 1995; Perrons et al., 1996; Vago et al., 1996; Weber et al., 1994). In most of these studies, the studied population consisted of HIV patients and healthy controls. However, three studies (Alvarez-Lafuente et al., 2007; Ferrante et al., 1998; Iacobaeus

Table 2

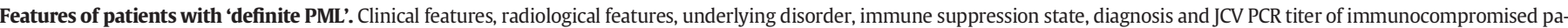

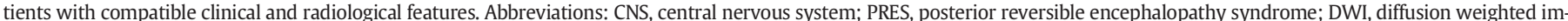
aging; T1+, enhancement on T1 with Gadolinium; SLE, systemic lupus erythematosus; HIV, human immunodeficiency virus; AIDS, acquired immunodeficiency syndrome.

\begin{tabular}{|c|c|c|c|c|c|c|}
\hline & Diagnosis & Clinical features & Radiological features & Underlying disorder & $\begin{array}{l}\text { Immune } \\
\text { suppression }\end{array}$ & JCV titer (log copies) \\
\hline 1 & PML & $\begin{array}{l}\text { Subacute focal neurological } \\
\text { deficit }\end{array}$ & $\begin{array}{l}\text { Multifocal T2 \& DWI hyperintense } \\
\text { lesions }\end{array}$ & SLE & Mycophenolate & 6.32 \\
\hline 2 & PML & $\begin{array}{l}\text { Subacute focal neurological } \\
\text { deficit }\end{array}$ & Multifocal T2 hyperintense lesions & $\begin{array}{l}\text { Hematological } \\
\text { malignancy }\end{array}$ & Rituximab & $<2.70$ \\
\hline 3 & PML & $\begin{array}{l}\text { Subacute focal neurological } \\
\text { deficit }\end{array}$ & Multifocal T2 hyperintense lesions & Solid organ transplant & $\begin{array}{l}\text { Mycophenolate } \\
\text { Cyclosporine }\end{array}$ & 3.54 \\
\hline 4 & PML & $\begin{array}{l}\text { Subacute focal neurological } \\
\text { deficit }\end{array}$ & Multifocal T2 hyperintense lesions & HIV & AIDS & 5.06 \\
\hline 5 & PML & $\begin{array}{l}\text { Subacute focal neurological } \\
\text { deficit }\end{array}$ & Multifocal T2 hyperintense lesions & HIV & AIDS & 4.60 \\
\hline 6 & PML & $\begin{array}{l}\text { Subacute focal neurological } \\
\text { deficit }\end{array}$ & Multifocal T2 hyperintense lesions & $\begin{array}{l}\text { Hematological } \\
\text { malignancy }\end{array}$ & Rituximab & $>6.70$ \\
\hline 7 & PML & $\begin{array}{l}\text { Subacute focal neurological } \\
\text { deficit }\end{array}$ & Multifocal T2 hyperintense lesions & Solid organ transplant & $\begin{array}{l}\text { Mycophenolate } \\
\text { Tacrolimus }\end{array}$ & 3.39 \\
\hline 8 & PML & $\begin{array}{l}\text { Subacute focal neurological } \\
\text { deficit }\end{array}$ & $\begin{array}{l}\text { Multifocal T2 \& DWI hyperintense } \\
\text { lesions }\end{array}$ & $\begin{array}{l}\text { Hematological } \\
\text { malignancy }\end{array}$ & Leukopenia & 4.38 \\
\hline 9 & PML & $\begin{array}{l}\text { Subacute focal neurological } \\
\text { deficit }\end{array}$ & Multifocal T2 hyperintense lesions & Bone marrow transplant & Cyclosporine & 3.02 \\
\hline 10 & PML & $\begin{array}{l}\text { Subacute focal neurological } \\
\text { deficit }\end{array}$ & Multifocal T2 hyperintense lesions & HIV & AIDS & 2.99 \\
\hline 11 & PML & $\begin{array}{l}\text { Subacute focal neurological } \\
\text { deficit }\end{array}$ & Multifocal T2 hyperintense lesions & $\begin{array}{l}\text { Hematological } \\
\text { malignancy }\end{array}$ & Rituximab & 2.82 \\
\hline 12 & PML & $\begin{array}{l}\text { Subacute focal neurological } \\
\text { deficit }\end{array}$ & Multifocal T2 hyperintense lesions & HIV & AIDS & 3.90 \\
\hline 13 & CNS lymphoma & $\begin{array}{l}\text { Subacute focal neurological } \\
\text { deficit }\end{array}$ & Multifocal T2 hyperintense lesions & Solid organ transplant & Rituximab & $<2.70$ \\
\hline 14 & CNS cystinosis & Subacute cognitive deterioration & $\mathrm{T} 2$ hyperintense lesion & Solid organ transplant & Cyclosporine & $<2.70$ \\
\hline 15 & CNS lymphoma & $\begin{array}{l}\text { Subacute focal neurological } \\
\text { deficit }\end{array}$ & $\mathrm{T} 2$ and $\mathrm{T} 1+$ hyperintense lesion & HIV & AIDS & $<2.70$ \\
\hline 16 & $\begin{array}{l}\text { Septic } \\
\text { embolisms }\end{array}$ & $\begin{array}{l}\text { Subacute focal neurological } \\
\text { deficit }\end{array}$ & Multifocal T2 hyperintense lesions & Gynecological malignancy & Chemotherapy & $<2.70$ \\
\hline 17 & PRES & Seizures & Multifocal T2 hyperintense lesions & Solid organ transplant & Tacrolimus & $<2.70$ \\
\hline
\end{tabular}




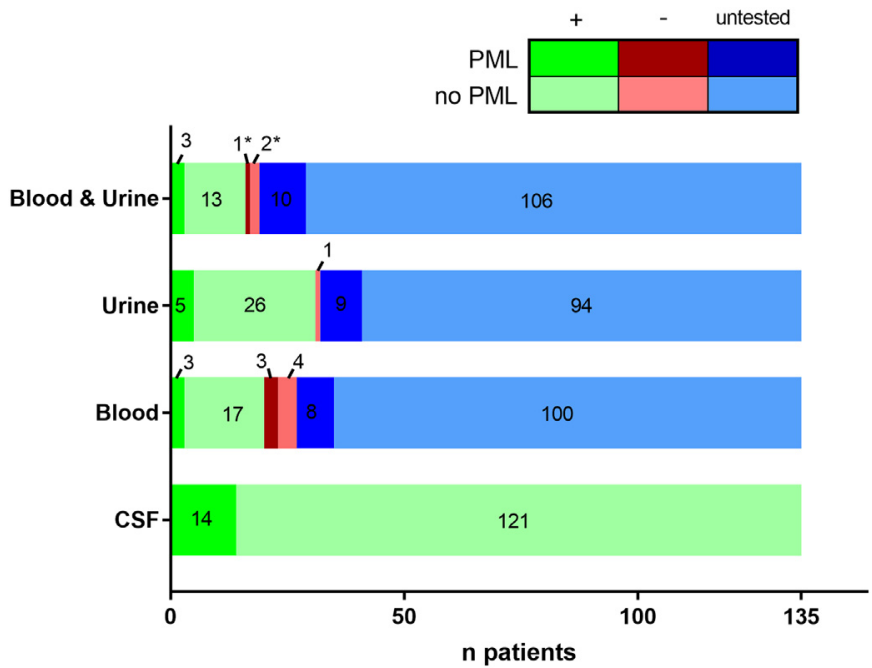

Fig. 3. JCV PCR in blood and urine. Representation of the distribution of the 135 index patients with positive CSF JCV PCR according to qualitative result of JCV PCR on blood and/or urine. PML cases are indicated in dark shades. The patients indicated with an asterisk $\left(^{*}\right)$ had a negative PCR in blood and a positive PCR in urine.

et al., 2009) investigated multiple sclerosis (MS) patients, one study (Behzad-Behbahani et al., 2003) investigated patients with meningitis or encephalitis and one study (Iacobaeus et al., 2013) investigated patients with neuropsychiatric systemic lupus erythematosus. Only four of the studies were published less than 15 years ago (Alvarez-Lafuente et al., 2007; Fink et al., 2006; lacobaeus et al., 2009, 2013). Only four of the studies used a quantitative method (Alvarez-Lafuente et al., 2007; Iacobaeus et al., 2009, 2013; Koralnik et al., 1999). Pooling of these literature data showed that CSF JCV PCR was positive in 152 of 174 PML cases while it was falsely positive in 31 of 1847 controls, resulting in a sensitivity of $87.4 \%$ (95\% CI: 81.6-91.5\%), a specificity of $98.3 \%$ (95\% CI: 97.6-98.8\%) and a PPV of $83.1 \%$ (95\% CI: $77.0-87.8 \%)$.

\section{Discussion}

We evaluated the performance of JCV PCR on CSF, blood and urine for the diagnosis of PML in clinical practice. Although sensitivity and specificity was not deducible from our data, we calculated a PPV of $10.4 \%$ for a positive CSF JCV PCR. This is significantly lower than the $83.1 \%$ derived from literature. There are several possible explanations for this.
First, since the PCRs in this study have been performed in a realworld clinical context, no indication criteria were applied and the decision to perform CSF JCV PCR was at the discretion of the treating physician. Since PML has a very low prevalence, the low PPV might reflect a relatively high index of suspicion for PML among physicians. Indeed, the majority (57.0\%) of patients didn't exhibit compatible clinical or radiological features at the time of the lumbar puncture and a considerable proportion (32.6\%) of patients was not immunocompromised. However, even in immunocompromised patients with both compatible clinical and radiological features (i.e. 'definite PML') the PPV was only $70.6 \%$, indicating that even in patients with a solid indication for CSF JCV PCR testing a false-positive result is frequent.

Second, there is an important difference in the constitution of the control population (i.e. non-PML patients). The studies reported so far made use of selected groups of control patients (mostly HIV and MS patients) who were often even asymptomatic. On the contrary, our control population was composed of clinical cases among whom PML was often in the differential diagnosis. We believe that these, often critically ill, patients have a higher chance of hematogenic or urinary contamination of the liquor sample, either in vivo or during lumbar puncture. The finding in our series that the vast majority of CSF positive patients also has a positive blood and/or urine JCV PCR (if tested) supports this hypothesis.

Third, because of the real-world clinical context, with CSF samples often analyzed at the same moment as highly positive urine or blood samples, a non-specific reaction in some CSF samples during PCR might explain some false-positive samples. Accordingly, since the implementation of repeated testing of weakly positive samples a lower false-positive rate has indeed been observed.

Fourth, since this is a single center study, it is likely that differences in technique (e.g. PCR primers) may be partially responsible for the difference in PPV observed when compared to published series. Of notice, since the PCR method used here is also able to detect BK polyomavirus DNA, some false-positive PCRs might be explained by presence of BK polyomavirus DNA in the CSF sample. Also, the PCR assay used is an in-house test with a limit of quantification set at 500 copies/mL based on plasmid as mentioned in Herman et al. (Herman et al., 2004). The limit of detection was later on determined at 300 copies $/ \mathrm{mL}$. It is important to realize that results of this type of studies may differ, given the differences in performance characteristics of the assays used and the fact that there is no standardization of JCV PCR assays. This also explains the large range in the PPV (0 to 100\%) of JCV PCR to diagnose PML found in literature. On the other hand, since most reported studies were performed more than 15 years ago, it is likely that the current PCR method has a higher sensitivity than before, implicating that weakly positive CSF samples might have been missed previously. The finding that, when stratified/dichotomized, a weakly positive CSF JCV

Table 3

Literature review Literature review of CSF JCV PCR in PML patients and controls. Fifteen studies were identified, with an overall positive predictive value of 83.1\%.

\begin{tabular}{|c|c|c|c|c|c|c|}
\hline Study & Quantitative PCR? & PML (n) & Controls (n) & $\begin{array}{l}\text { True } \\
\text { positive (n) }\end{array}$ & False positive (n) & PPV (\%) \\
\hline Gibson et al. (1993) & No & 13 & 41 & 10 & 0 & 100.0 \\
\hline Weber et al. (1994) & No & 3 & 30 & 3 & 0 & 100.0 \\
\hline Fong et al., (1995) & No & 23 & 48 & 17 & 2 & 89.5 \\
\hline McGuire et al. (1995) & No & 26 & 130 & 24 & 11 & 68.6 \\
\hline Hammarin et al. (1996) & No & 20 & 192 & 20 & 0 & 100 \\
\hline Vago et al. (1996) & No & 13 & 16 & 8 & 0 & 100 \\
\hline Perrons et al. (1996) & No & 23 & 67 & 19 & 0 & 100 \\
\hline Ferrante et al. (1997) & No & 12 & 52 & 11 & 0 & 100 \\
\hline Ferrante et al. (1998) & No & 0 & 175 & 0 & 11 & 0.0 \\
\hline Koralnik et al. (1999) & Yes & 14 & 92 & 13 & 1 & 92.9 \\
\hline Behzad-Behbahani et al. (2003) & No & 0 & 151 & 0 & 2 & 0.0 \\
\hline Fink et al. (2006) & No & 27 & 143 & 27 & 1 & 96.4 \\
\hline Alvarez-Lafuente et al. (2007) & Yes & 0 & 73 & 0 & 2 & 0.0 \\
\hline Iacobaeus et al. (2009) & Yes & 0 & 515 & 0 & 1 & 0.0 \\
\hline Iacobaeus et al. (2013) & Yes & 0 & 122 & 0 & 0 & N/A \\
\hline TOTAL & & 174 & 1847 & 152 & 31 & 83.1 \\
\hline Current study & Yes & 14 & $N / A$ & 14 & 121 & 10.4 \\
\hline
\end{tabular}


PCR has a PPV of only $1.6 \%$ whereas a moderately to strongly positive PCR has a PPV of $92.3 \%$, supports this hypothesis. This latter rate approaches the range of the $83.1 \%$ calculated from literature data.

In total, we identified 121 patients with a false-positive CSF JCV PCR. Since the vast majority $(\mathrm{n}=120,99.2 \%)$ had a weakly positive $(<2.7 \mathrm{log}$ copies $/ \mathrm{mL}$ ) viral load, it could be argued to implement this threshold for diagnosis of PML. This is supported by the study by Iacobaeus et al. which identified one false-positive patient with a viral load of $2.01 \mathrm{log}$ copies/mL, falling within our range of 'weak positivity' $(<2.7 \mathrm{log}$ copies $/ \mathrm{mL}$ ) (Iacobaeus et al., 2009). Unfortunately, in the other studies of our literature search either a qualitative PCR method was used or the viral load was not mentioned. On the contrary, implementing/establishing a higher threshold will result in a significantly lower sensitivity for several reasons. First, in our series 2 out of 14 PML patients had a viral load of less than $2.7 \log$ copies/mL. Second, two small series (Clifford et al. (Clifford et al., 2010) and Dahlhaus et al. (Dahlhaus et al., 2013)) of patients with natalizumab associated PML reported a high rate of weakly positive $(<2.7 \log$ copies $/ \mathrm{mL})$ CSF JCV PCRs $(57 \%$ and 53\%, respectively). Third, several cases of PML with negative CSF JCV PCR (i.e. 'false negatives') have been reported (Babi et al., 2015; Landry et al., 2008). So implementing a threshold around 2.7 log copies (e.g. 2.82 based on the present ROC analysis) would indeed give rise to a considerable reduction of false-positive PCRs, but in turn some PML patients would be missed.

We observed a PPV of CSF JCV PCR of 0.0\% in immunocompetent patients as well as in patients without compatible clinical or radiological features, indicating that CSF JCV PCR testing should be reserved for patients with a certain degree of clinical suspicion of PML, as suggested by the current diagnostic criteria (Berger et al., 2013). On the other hand, this also implies that a positive CSF JCV PCR in a patient without any clinicoradiological suspicion of PML (i.e. 'coincidentally positive') is almost always false positive and hence no further measures, except repeated PCR testing, should be taken. On the other end of the diagnostic spectrum, PPV of CSF JCV PCR in immunocompromised patients with compatible clinical and radiological features (i.e. the highest clinical suspicion possible) was $70.6 \%$, supporting the view of restrictive indication for CSF JCV PCR testing. However, this also implies that almost one out of three patients with 'definite PML' according to the diagnostic criteria eventually turns out not to have PML. This suggests clinicians should be on the outlook not to miss alternative (often treatable) diagnoses. Importantly, taking into account the quantitative aspect (i.e. viral load) of the PCR increased the PPV to $100.0 \%$ and may thus be of critical aid in solidifying the diagnosis. Similarly, in patients with 'probable PML' the PPV was only 8.3\%, while taking into account the viral load increased the PPV to $100.0 \%$, again indicating the importance of the viral load and exclusion of alternative diagnoses.

We observed that repeated testing of weakly positive samples significantly decreases the rate of false-positive PCRs. This indicates that, in spite of rigorous laboratory protocols and precautions, the PCR can still be falsely positive. This is of high clinical importance, especially in real-world clinical practice where the index of suspicion for PML is very high and JCV PCR testing is performed even in patients without compatible clinical and radiological features. Therefore, pretest probability is generally low in clinical practice. Repeated testing of weakly positive samples in a clinical context of diagnostic uncertainty may partially correct for this and is hence recommended. Generally, it is recommended to reserve CSF JCV PCR for patients with compatible clinical and/or radiological features. This is in line with the current diagnostic criteria for PML, where patients with a positive CSF JCV PCR in the absence of typical clinical and radiological features are considered 'possible PML' (Berger et al., 2013).

Predictive value of JCV PCR on urine and blood was low (Fig. 3). We could not identify a specific JCV PCR profile on CSF, blood and urine being highly suggestive of PML. In fact, it was clear that the majority of patients with a positive CSF JCV PCR also had a positive PCR on blood and urine (if tested). So JCV PCR on blood and urine has no additional value in the diagnosis of PML in patients with a positive CSF JCV PCR. We observed a relatively high proportion of positive JCV PCR in blood (i.e. $74.1 \%$ - 20 out of 27 tested individuals), which is markedly higher than the supposed proportion of JCV viremia in healthy individuals (ranging from 0\% to 30\% (Boukoum et al., 2016; Delbue et al., 2007; Haghighi et al., 2019; Rocca et al., 2015)). However, a significantly higher proportion has been noted in several disease states (e.g. 46.1\% in MS patients (Delbue et al., 2007) and 67\% in HIV patients (Rocca et al., 2015)). Therefore, as the majority of patients in our cohort was immunocompromised and/or seriously ill, this proportion is actually in line with previous data.

To conclude, in clinical practice a moderately to strongly positive CSF JCV PCR (i.e. $\geq 2.7 \log$ copies $/ \mathrm{mL}$ ) is strongly suggestive of PML. In case of a weakly positive CSF JCV PCR (i.e. $<2.7 \log$ copies $/ \mathrm{mL}$ ) diagnosis of PML is unlikely but not excluded, and repeated testing is recommended. $\mathrm{Al}$ together it seems prudent not to rely blindly on the qualitative result of a CSF JCV PCR in the diagnosis of PML, but to consider the quantitative result (i.e. viral load) together with clinical and radiological data.

\section{Acknowledgements}

Bart Swinnen, Geert Meyfroidt and Maarten Schrooten are supported by the fund for Scientific Research Flanders (FWO; PhD fellowship 11 Y9515N, senior clinical investigatorship $1846113 \mathrm{~N}$ and clinical PhD fellowship $1701413 \mathrm{~N}$, respectively).

\section{Conflict of interest}

The authors declare that they have no conflict of interest.

\section{Author contributions}

BS and MS acquired, analyzed and interpreted the data and performed a literature research. VS was involved with microbiological testing and conducted the database query. $\mathrm{KB}$ was involved with microbiological testing. VS, GM, GC and AW analyzed and interpreted the data. All authors were involved in drafting and revising the manuscript.

\section{References}

Alvarez-Lafuente R, Garcia-Montojo M, De Las Heras V, Bartolome M, Arroyo R. JC virus in cerebrospinal fluid samples of multiple sclerosis patients at the first demyelinating event. Mult Scler 2007:13:590-5.

Babi M-A, Pendlebury W, Braff S, Waheed W. JC Virus PCR Detection Is Not Infallible: A 12 Fulminant Case of Progressive Multifocal Leukoencephalopathy with False-Negative 13 Cerebrospinal Fluid Studies despite Progressive Clinical Course and Radiological Findings. Case Rep Neurol Med 2015;2015:1-4

Bauer J, Gold R, Adams O, Lassmann H. Progressive multifocal leukoencephalopathy and 16 immune reconstitution inflammatory syndrome (IRIS). Acta Neuropathol 2015; 130:751-64.

Behzad-Behbahani A, Klapper P, Vallely P, Cleator G, Bonington A. BKV-DNA and JCV-DNA in 18 CSF of patients with suspected meningitis or encephalitis. Infection 2003;31: 374-8.

Berger JR, Aksamit AJ, Clifford DB, Davis L, Koralnik I, al Sejvar Jet. PML diagnostic criteria; 20 Consensus statement from the AAN Neuroinfectious Disease Section. Neurology 2013;80:1430-8.

Beuselinck K, Van Ranst M, Van Eldere J. Automated extraction of viral-pathogen RNA and 22 DNA for high-throughput quantitative real-time PCR. J Clin Microbiol 2005;43: 5541-6.

Boukoum H, Nahdi I, Sahtout W, Skiri H, Segondy M, Aouni M. BK and JC virus infections in 24 healthy patients compared to kidney transplant recipients in Tunisia. Microb Pathog 2016;97:204-8.

Clifford DB, DeLuca A, Simpson DM, Arendt G, Giovannoni G, Nath A. Natalizumab-associated progressive multifocal leukoencephalopathy in patients with multiple sclerosis: lessons from 28 cases. Lancet Neurol 2010;9:438-46.

Dahlhaus S, Hoepner R, Chan A, Kleiter I, Adams O, Lukas C, et al. Disease course and outcome of 15 monocentrically treated natalizumab-associated progressive multifocal leukoencephalopathy patients. J Neurol Neurosurg Psychiatry 2013;84:1068-74

Delbue S, Guerini FR, Mancuso R, Caputo D, Mazziotti R, al Saresella Met. JC virus viremia in interferon-P-treated and untreated Italian multiple sclerosis patients and healthy controls. J Neuro-Oncol 2007;13:73-7. 
Ferrante P, Caldarelli-Stefano R, Omodeo-Zorini E, Cagni a E, Cocchi L, Suter F, et al. Comprehensive investigation of the presence of JC virus in AIDS patients with and without 37 progressive multifocal leukoencephalopathy. J Med Virol 1997;52:235-42.

Ferrante P, Omodeo-Zorini E, Caldarelli-Stefano R, Mediati M, Fainardi E, Granieri E, et al. Detection of JC virus DNA in cerebrospinal fluid from multiple sclerosis patients. Mult Scler 1998;4:49-54.

Fink MCDS, Penalva de Oliveira AC, Milagres FAP, Vidal JE, Picerno-Pouza AF, Duarte Neto A, et al. JC virus DNA in cerebrospinal fluid samples from Brazilian AIDS patients with focal brain lesions without mass effect. J Infect 2006;52:30-6.

Fong IW, Britton CB, Luinstra KE, Toma E. Diagnostic value of detecting JC virus DNA in cerebrospinal fluid of patients with progressive multifocal leukoencephalopathy. J Clin Microbiol 1995;33:2-5.

Gibson P, Knowles W, Hand J, Brown D. Detection of JC virus DNA in the cerebrospinal fluid of patients with progressive multifocal leukoencephalopathy. J Med Virol 1993;39:278-81.

Haghighi MF, Seyyedi N, Farhadi A, Zare F, Kasraian L, al Refiei Dehbidi GRet Polyomaviruses BK and JC DNA infection in peripheral blood cells from blood donors. Braz J Infect Dis 2019;23:22-6.

Hammarin A, Bogdanovic G, Svedhem V. Analysis of PCR as a tool for detection of JC virus DNA in cerebrospinal fluid for diagnosis of progressive multifocal leukoencephalopathy. J Clin Microbiol 1996;34:2929-32.

Herman J, Van Ranst M, Snoeck R, Beuselinck K, Lerut E, Van Damme-Lombaerts R. Polyomavirus infection in pediatric renal transplant recipients: evaluation using a quantitative real-time PCR technique. Pediatr Transplant 2004;8:485-92.

Koralnik I, Boden D, Mai V, Lord C, Letvin N. JC virus DNA load in patients with and without progressive multifocal leukoencephalopathy. Neurology 1999;52:253-60. lacobaeus E, Hopia L, Khademi M, Lunden M, Hammarin A-L, al Svenungsson Eet. Analysis of JC virus DNA in NPSLE patients treated with different immunomodulatory agents. Lupus 2013;22:307-11.

lacobaeus E, Ryschkewitsch C, Gravell M, Khademi M, Wallstrom E, al Olsson Tet. Analysis of cerebrospinal fluid and cerebrospinal fluid cells from patients with multiple sclerosis for detection of JC virus DNA. Mult Scler 2009;15:28-35.

Landry M, Eid T, Bannykh S, Major E. False negative PCR despite high levels of JC virus DNA in spinal fluid: Implications for diagnostic testing. J Clin Virol 2008;43:247-9.

McGuire D, Barhite S, Hollander $H$, Miles M. JC virus DNA in cerebrospinal fluid of human immunodeficiency virus-infected patients: predictive value for progressive multifocal leukoencephalopathy. Ann Neurol 1995;37:395-9.

Perrons C, Fox J, Lucas S, Brink N, Tedder R, Miller R. Detection of polyomaviral DNA in clinical samples from immunocompromised patients: correlation with clinical disease. J Infect 1996;32:205-9.

Rocca A, Martelli F, Delbue S, Ferrante P, Bartolozzi D, al Azzi Aet. The JCPYV DNA load inversely correlates with the viral microrna expression in blood and cerebrospinal fluid of patients at risk of PML. J Clin Virol 2015;70:1-6.

Vago L, Cinque P, Sala E, Nebuloni M, Caldarelli R, al Racca Set. JCV-DNA and BKV-DNA in the CNS tissue and CSF of AIDS patients and normal subjects. Study of 41 cases and review of the literature. J Acquir Immune Defic Syndr Hum Retrovirol 1996;12: 139-46.

Weber T, Turner R, Frye S, Luke W, Kretzschmar H, al Luer Wet. Progressive multifocal leukoencephalopathy diagnosed by amplification of JC virus-specific DNA from cerebrospinal fluid. AIDS 1994;8:49-57. 